\title{
Correlation of vascular endothelial function and coagulation factors with renal function and inflammatory factors in patients with diabetic nephropathy
}

\author{
JIE SUN and CAIYAN LIU \\ Department of Endocrinology, The 89th Hospital of the People's Liberation Army, \\ Weifang, Shandong 261041, P.R. China
}

Received March 14, 2018; Accepted August 30, 2018

DOI: $10.3892 / \mathrm{etm} .2018 .6718$

\begin{abstract}
Correlation of vascular endothelial function and coagulation factors with renal function and inflammatory factors in patients with diabetic nephropathy was analyzed. A total of 86 patients diagnosed with diabetes mellitus (DM) and admitted to the 89th Hospital of the People's Liberation Army (Weifang, China) from March 2014 to May 2017 were selected. Among them, 38 patients complicated with nephropathy were divided into the observation group and 48 patients without nephropathy into the control group. The general data of patients were collected, and the relevant biochemical indexes, vascular endothelial function, coagulation factors and renal function indicators and the levels of inflammatory factors were determined. In the observation group, the duration of DM was longer than that in the control group, and the levels of glycated hemoglobin (HbAlc), fasting plasma glucose (FPG) and fasting insulin (FINS), level of fibrinogen (FIB) were higher than those in the control group $(\mathrm{p}<0.05)$. Homocysteine (Hcy) and brachial artery blood flow in the observation group were higher than those in the control group. The levels of nitric oxide (NO) and flow-mediated dilation (FMD) were lower than those in the control group $(\mathrm{p}<0.05)$. Activated partial thromboplastin time (APTT) in the observation group was shorter than that in the control group $(\mathrm{p}<0.05)$. The levels of cystatin- $\mathrm{C}(\mathrm{Cys}-\mathrm{C})$, serum creatinine $(\mathrm{SCr})$, urea and $\beta 2$-microglobulin, levels of $\mathrm{C}$-reactive protein (CRP), tumor necrosis factor- $\alpha$ (TNF- $\alpha$ ) and interleukin-6 (IL-6) in peripheral serum in the observation group were greatly higher than those in the control group $(\mathrm{p}<0.05)$. It was concluded via the correlation analysis of vascular endothelial function and coagulation factor with renal function and inflammatory factors that $\mathrm{SCr}$ and $\mathrm{CRP}$
\end{abstract}

Correspondence to: Dr Caiyan Liu, Department of Endocrinology, The 89th Hospital of the People's Liberation Army, 256 Beigong Xi Street, Weifang, Shandong 261041, P.R. China

E-mail: ywa6en@163.com

Key words: diabetic nephropathy, vascular endothelial function, coagulation factor, renal function, inflammatory factor were negatively correlated with $\mathrm{NO}$, and $\mathrm{SCr}$ and $\mathrm{CRP}$ were positively correlated with FIB. Serum inflammatory factors, coagulation function and vascular endothelial function are closely related to diabetic nephropathy, which are good reference indexes for the assessment of diabetic nephropathy.

\section{Introduction}

At present, the aging phenomenon of social population is increasingly obvious. The incidence of diabetes mellitus (DM) is higher each year all over the world as a result of many factors such as genetic factors, environment and social life style (1). The latest survey data show that in China there are $>30$ million DM patients aged $>45$ years (2), and most of the patients with chronic renal insufficiency are DM patients whose common clinical manifestation are proteinuria and gradual decline of renal function (3). With a rather complex pathogenesis, type 2 DM is the main type among DM patients. The inflammatory response plays important roles in the occurrence and deve lopment of diabetic nephropathy. C-reactive protein (CRP), tumor necrosis factor- $\alpha$ (TNF- $\alpha$ ), and interleukin-6 (IL-6) play main roles in promoting the inflammatory response among the systemic inflammatory responses, regulating the patient's immune and inflammatory response system $(4,5)$. Numerous studies have concluded that the long-term blood hypercoagulability is one of the major causes of impaired renal function in DM patients (6). In the presence of proteinuria in patients with diabetic nephropathy, the activity of coagulation factors in plasma is stronger than that in the normal organism. In particular, endogenous coagulation factors affect coagulation function in patients with one another (7). On the other hand, the number of glomerular and tubular interstitial capillaries of patients with diabetic nephropathy is smaller than that in the normal organism. The decrease in the number of capillaries is mainly due to apoptosis and clearance of vascular endothelial cells (8). In the adult organism, the normal function of the vascular endothelial cells is maintained through continuous proliferation of vascular endothelial cells to form new vascular histiocytic germs (9). Vascular endothelial cell is also one of the most important human endocrine tissues, which can synthesize and release a large amount of vasoactive substances, affecting vital organs of the body such as kidney and liver (7). 
Therefore, investigating the relationships of vascular endothelial function and coagulation factors with renal function and levels of serum inflammatory factors in patients with diabetic nephropathy may provide a new clinical reference value for the diagnosis and treatment of patients with diabetic nephropathy.

\section{Patients and methods}

General data. A total of 86 patients diagnosed with DM and admitted to the 89th Hospital of the People's Liberation Army (Weifang, China) from March 2014 to May 2017 were selected. Among them, 38 patients with nephropathy were divided into the observation group and 48 patients without nephropathy into the control group. There were 45 males and 41 females aged $45-78$ years with an average age of $52.73 \pm 8.68$ years. The patients enrolled met the diagnostic criteria of World Health Organization (WHO) type 2 DM of 1997. The diagnostic criteria of diabetic nephropathy were based on renal function, 24-h urinary protein and urinary protein-creatinine ratio. Exclusion criteria: i) patients with severe systemic infection; ii) patients who used estrogen, anti-coagulant or thrombolytic drugs; iii) patients with malignant tumor; iv) patients with autoimmune diseases; v) patients with severe liver and kidney dysfunction; vi) patients with mental illness; and vii) patients with missing clinical data or who refused to sign the informed consent.

The study was approved by the Ethics Committee of the 89th Hospital of the People's Liberation Army. Patients who participated in this study or their guardians, signed informed consent and had complete clinical data.

Methods. All clinical data of patients including age, sex, height, weight and duration of DM were retrospectively analyzed. Fasting peripheral blood in all the patients after fasting and water deprivation overnight for $10 \mathrm{~h}$ were collected. The upper serum was taken to determine the relevant biochemical indicators. The fasting plasma glucose (FPG) was determined by glucose oxidase method. The glycated hemoglobin (HbA1c) was detected via glycohemoglobin analyzer. The fasting insulin (FINS) level was estimated via radioimmunity method with the kit provided by Beijing Kepu Science and Technology Co., Ltd. (Beijing, China). The levels of total cholesterol (TC), triglyceride (TG), low-density lipoprotein cholesterol (LDL-C), high-density lipoprotein cholesterol (HDL-C) and renal function indicators such as cystatin-C (Cys-C), serum creatinine ( $\mathrm{SCr}$ ), urea, $\beta 2$-microglobulin were detected by the automatic biochemistry analyzer (Beckman-700, Fullerton, CA, USA). The levels of CRP, TNF- $\alpha$ and IL- 6 were determined through immune turbidimetry. Immunomagnetic bead assay was used to detect the fibrinogen (FIB), prothrombin time (PT) and activated partial thromboplastin time (APTT). Homocysteine (Hcy) and nitric oxide (NO) were detected through enzyme-linked immunosorbent assay (ELISA). Brachial artery blood flow and endothelium-dependent vasodilation through flow-mediated dilation (FMD) were measured via two-dimensional ultrasound.

Statistical analysis. Statistical Product and Service Solutions (SPSS; IBM Corp., Armonk, NY, USA) 19.0 software was used for data processing. Data were collected and presented as
Table I. Comparison of general information between the observation and control groups.

\begin{tabular}{lccc}
\hline $\begin{array}{l}\text { General } \\
\text { information }\end{array}$ & $\begin{array}{c}\text { Observation } \\
\text { group }(\mathrm{n}=38)\end{array}$ & $\begin{array}{c}\text { Control } \\
\text { group }(\mathrm{n}=48)\end{array}$ & P-value \\
\hline Age (years) & $53.17 \pm 8.36$ & $51.93 \pm 7.93$ & 0.682 \\
Sex (male/female) & $20 / 18$ & $25 / 23$ & 0.591 \\
BMI $\left(\mathrm{kg} / \mathrm{m}^{2}\right)$ & $23.91 \pm 3.82$ & $24.08 \pm 2.77$ & 0.424 \\
DM duration (years) & $10.79 \pm 2.53$ & $6.36 \pm 3.17$ & 0.013 \\
HbA1c $(\%)$ & $10.99 \pm 1.47$ & $7.23 \pm 1.05$ & 0.003 \\
FPG $(\mathrm{mmol} / \mathrm{l})$ & $11.39 \pm 1.76$ & $8.27 \pm 0.95$ & 0.001 \\
FINS $(\mathrm{mIU} / \mathrm{l})$ & $13.75 \pm 2.41$ & $9.79 \pm 2.34$ & 0.001 \\
TC $(\mathrm{mmol} / \mathrm{l})$ & $5.75 \pm 1.21$ & $4.84 \pm 1.05$ & 0.071 \\
TG $(\mathrm{mmol} / \mathrm{l})$ & $1.95 \pm 1.03$ & $1.93 \pm 0.98$ & 0.116 \\
LDL-C $(\mathrm{mmol} / \mathrm{l})$ & $3.11 \pm 0.97$ & $2.97 \pm 0.86$ & 0.493 \\
HDL-C $(\mathrm{mmol} / \mathrm{l})$ & $1.48 \pm 0.51$ & $1.43 \pm 0.29$ & 0.078 \\
\hline
\end{tabular}

BMI, body mass index; DM, diabetes mellitus; HbA1c, glycated hemoglobin; FPG, fasting plasma glucose; FINS, fasting insulin; TC, total cholesterol; TG, triglyceride; LDL-C, low-density lipoprotein cholesterol; HDL-C, high-density lipoprotein cholesterol.

Table II. Comparison of vascular endothelial function between the observation and control groups.

\begin{tabular}{lccc}
\hline Related index & $\begin{array}{c}\text { Observation } \\
\text { group }(\mathrm{n}=38)\end{array}$ & $\begin{array}{c}\text { Control } \\
\text { group }(\mathrm{n}=48)\end{array}$ & P-value \\
\hline Hcy $(\mu \mathrm{mol} / \mathrm{l})$ & $29.56 \pm 4.57$ & $13.23 \pm 2.91$ & 0.001 \\
NO $(\mu \mathrm{mol} / \mathrm{l})$ & $41.87 \pm 9.86$ & $69.85 \pm 11.78$ & 0.013 \\
Brachial artery & & & \\
blood flow (ml/min) & $79.79 \pm 26.31$ & $71.33 \pm 25.29$ & 0.019 \\
FMD $(\%)$ & $3.49 \pm 0.26$ & $4.73 \pm 0.41$ & 0.001 \\
\hline
\end{tabular}

Hcy, homocysteine; NO, nitric oxide; FMD, flow-mediated dilation.

(means $\pm \mathrm{SD}$ ), and Chi-square test was used for the comparison of enumeration data. Pearson's correlation analysis was used between the two factors. $\mathrm{P}<0.05$ suggested that the diffidence was statistically significant.

\section{Results}

Comparison of general information between the observation and control groups. The differences in age, sex, body mass index (BMI), TC, TG, LDL-C and HDL-C were not statistically significant between the observation and control groups. However, the DM duration in the observation group was longer than that in the control group, and levels of HbA1c, FPG and FINS were significantly higher than those in the control group. All the differences were statistically significant $(\mathrm{p}<0.05$, Table I).

Comparison of vascular endothelial functions between the observation and control groups. In the observation group, 
Table III. Comparison of coagulation function between the observation and control groups.

\begin{tabular}{lrrr}
\hline $\begin{array}{l}\text { Coagulation } \\
\text { function }\end{array}$ & $\begin{array}{c}\text { Observation } \\
\text { group }(\mathrm{n}=38)\end{array}$ & $\begin{array}{c}\text { Control } \\
\text { group }(\mathrm{n}=48)\end{array}$ & P-value \\
\hline FIB $(\mathrm{g} / \mathrm{l})$ & $4.49 \pm 0.83$ & $2.82 \pm 0.76$ & 0.026 \\
PT $(\mathrm{sec})$ & $11.93 \pm 1.31$ & $12.08 \pm 1.45$ & 0.573 \\
APTT $(\mathrm{sec})$ & $30.88 \pm 2.79$ & $35.06 \pm 3.07$ & 0.046 \\
\hline
\end{tabular}

FIB, fibrinogen; PT, prothrombin time; APTT, activated partial thromboplastin time.

Table IV. Comparison of renal function levels between the observation and control groups.

\begin{tabular}{lccc}
\hline Related index & $\begin{array}{c}\text { Observation } \\
\text { group }(\mathrm{n}=38)\end{array}$ & $\begin{array}{c}\text { Control } \\
\text { group }(\mathrm{n}=48)\end{array}$ & P-value \\
\hline Cys-C $(\mu \mathrm{mol} / \mathrm{l})$ & $1.47 \pm 0.35$ & $0.96 \pm 0.17$ & 0.001 \\
$\mathrm{SCr}(\mu \mathrm{mol} / \mathrm{l})$ & $67 \pm 9$ & $38 \pm 4$ & 0.001 \\
Urea $(\mathrm{mmol} / \mathrm{l})$ & $5.7 \pm 0.8$ & $2.9 \pm 0.5$ & 0.001 \\
$\beta 2-$ microglobulin $(\mathrm{mg} / \mathrm{l})$ & $4.3 \pm 0.3$ & $2.7 \pm 0.2$ & 0.001 \\
\hline
\end{tabular}

Cys-C, cystatin-C; $\mathrm{SCr}$, serum creatinine.

Table V. Comparison of levels of serum inflammatory factors between the observation and control groups.

\begin{tabular}{lrcc}
\hline $\begin{array}{l}\text { Inflammatory } \\
\text { factor }\end{array}$ & $\begin{array}{c}\text { Observation } \\
\text { group }(\mathrm{n}=38)\end{array}$ & $\begin{array}{c}\text { Control } \\
\text { group }(\mathrm{n}=48)\end{array}$ & P-value \\
\hline $\mathrm{CRP}(\mathrm{mg} / \mathrm{l})$ & $5.51 \pm 1.45$ & $2.43 \pm 0.99$ & 0.001 \\
$\mathrm{TNF}-\alpha(\mathrm{ng} / \mathrm{ml})$ & $10.98 \pm 1.34$ & $6.07 \pm 1.12$ & 0.001 \\
IL-6 $(\mu \mathrm{g} / \mathrm{l})$ & $9.57 \pm 1.65$ & $6.82 \pm 1.39$ & 0.001 \\
\hline
\end{tabular}

CRP, C-reactive protein; TNF- $\alpha$, tumor necrosis factor- $\alpha$; IL-6, interleukin-6.

the peripheral serum Hcy and brachial artery blood flow were higher than those in the control group, and NO and FMD levels were lower than those in the control group. The differences were statistically significant $(\mathrm{p}<0.05$, Table II).

Comparison of coagulation functions between the observation and control groups. As for the comparison between the two groups of patients, the difference in PT between the observation and control groups was not significant. But the level of FIB in the observation group was higher than that in the control group and APTT was shorter than that in the control group. All the differences were statistically significant $(\mathrm{p}<0.05$, Table III).

Comparison of renal function levels between the observation and control groups. The peripheral serum Cys-C, $\mathrm{SCr}$,

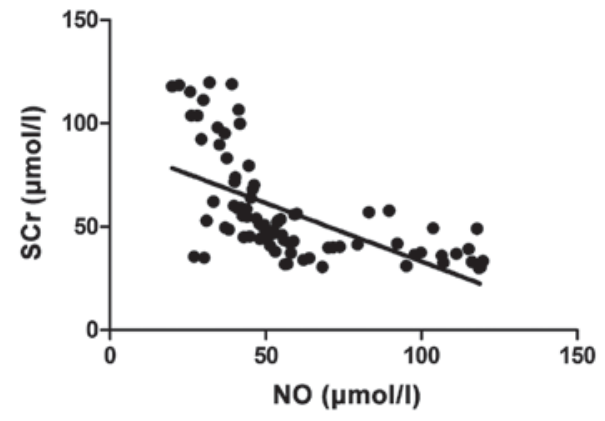

Figure 1. Correlation of NO with SCr. NO, nitric oxide; SCr, serum creatinine.

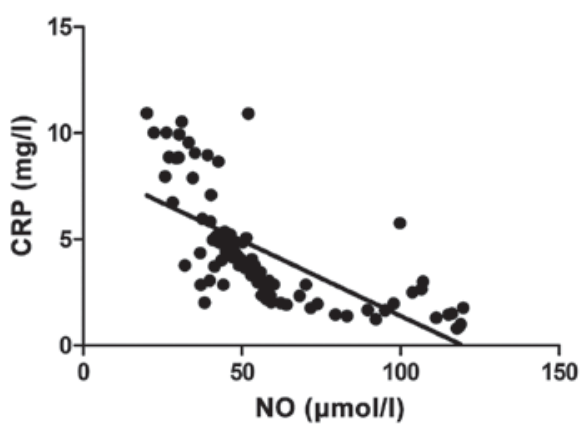

Figure 2. Correlation of NO with CRP. NO, nitric oxide; CRP, C-reactive protein.

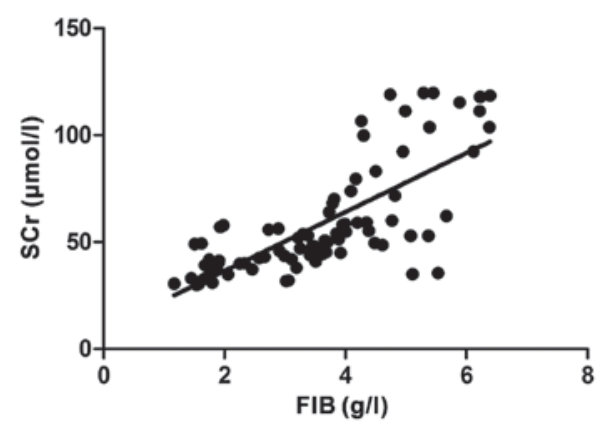

Figure 3. Correlation of FIB with SCr. FIB, fibrinogen; SCr, serum creatinine.

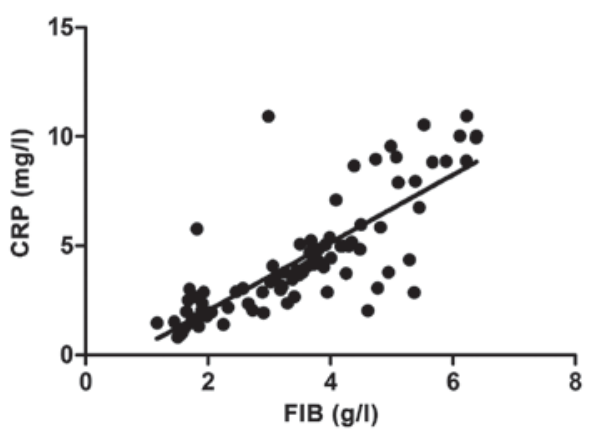

Figure 4. Correlation of FIB with CRP. FIB, fibrinogen; CRP, C-reactive protein.

urea and $\beta 2$-microglobulin levels in observation group were significantly higher than those in the control group and the differences were statistically significant $(\mathrm{p}<0.05$, Table IV). 
Comparison of levels of peripheral serum inflammatory factors between the observation and control groups. Levels of peripheral serum CRP, TNF- $\alpha$, IL-6 in the observation group were significantly higher than those in the control group and the differences were statistically significant $(\mathrm{p}<0.05$, Table V).

Analysis of correlation of vascular endothelial function and coagulation factors with renal function and inflammatory factors. $\mathrm{SCr}(\mathrm{r}=-0.683, \mathrm{p}<0.001)$ and $\mathrm{CRP}(\mathrm{r}=-0.696, \mathrm{p}<0.001)$ were negatively correlated with NO. SCr $(r=0.713, \mathrm{p}<0.001)$ and CRP ( $\mathrm{r}=0.747, \mathrm{p}<0.001)$ were positively correlated with FIB (Figs. 1-4).

\section{Discussion}

With the continuous changes in social lifestyle, including living environment, dietary habits and other changes, the incidence of DM is increasing. In particular, the incidence of DM is approximately $10 \%$ in China, most of which is type 2 DM (10). The dysfunction of blood glucose regulation results in the various target organ dysfunctions in the whole body. Vascular disease is the most common disease found in clinic. Diabetic nephropathy is one of the most common complications, which is manifested as impaired renal function and the presence of proteinuria (8). Diabetic nephropathy is a common cause of clinical chronic renal failure among many others, and the overreaction of inflammatory system plays an important pathogenic role in diabetic nephropathy (11). Type $2 \mathrm{DM}$ is often complicated with metabolic imbalance in adipocytes, which can produce more inflammatory factors than normal levels and thus resulting in an inflammatory response (12). The combination of diabetes with renal injury leads to the severe ongoing inflammatory system response (13). CRP, TNF- $\alpha$ and other factors play an important role in the inflammatory system response process. The inflammatory response causes the occurrence and aggravation of atherosclerosis, which is also an important factor contributing to the death of patients with diabetic nephropathy (14). The major role of IL-6 is to regulate the immune system and to transmit important information in the inflammatory system responses. TNF- $\alpha$ can enhance the stress response of cells to the inflammatory reaction, lead to insulin resistance and accelerate the renal injury in DM patients (15). It was found in this study that the levels of peripheral inflammatory factors in DM patients complicated with nephropathy were significantly higher than those in patients with simple DM, and the differences were statistically significant, which is consistent with the above conclusion $(\mathrm{p}<0.05)$.

Numerous studies have shown that DM patients have blood systems which are often manifested as hypercoagulability, and they are more prone to the thrombosis compared with healthy people (6). DM patients often have different degrees of thrombosis which results in increased mortality (16). Relevant data reveal that the thrombus activation for DM patients is stronger than that for normal body. A variety of plasma coagulation factors are increased in patients with DM, further aggravating renal injury (17). It was shown in this study that the levels of renal function-related indicators in patients with diabetic nephropathy were significantly higher than those in diabetic patients without renal injury and APTT was shorter, suggesting that patients with diabetic nephropathy have enhanced endogenous coagulation function. The main pathologic and physiological manifestations of DM patients are increased content of extracellular matrix, increased quantity of mesangial cells and glomerular sclerosis (18). Long duration of DM, long-term poor blood glucose control, endocrine metabolic disorders, the change of glomerular hemodynamics and other reasons are the main factors leading to the occurrence and aggravation of diabetic nephropathy (19). On the other hand, impaired vascular endothelial function is also closely related to diabetic nephropathy. Patients with long-term hyperglycemia are prone to vascular endothelial dysfunction; disorder of the active substances released from vascular synthesis, decreased level of vasodilator active factor and increased content of vasoconstrictor factors, and they are also easier to have vascular contracture and be exposed to the increased risk of thrombosis (20). It was concluded in the study that the blood of patients with diabetic nephropathy is hypercoagulable, and the degree of vascular endothelial dysfunction is more severe than that in patients only with diabetes. The difference was statistically significant $(\mathrm{p}<0.05)$. Therefore, paying close attention to the peripheral serum inflammatory factors, coagulation factors and endothelial function in patients with diabetic nephropathy will help to determine and treat the disease, improve the prognosis, reduce mortality and provide new ideas for the treatment of patients with diabetic nephropathy.

\section{Acknowledgements}

Not applicable.

\section{Funding}

No funding was received.

\section{Availability of data and materials}

The datasets used and/or analyzed during the present study are available from the corresponding author on reasonable request.

\section{Authors' contributions}

JS contributed to writing the manuscript as well as collected and analyzed all clinical data of patients. CL analyzed and interpreted the vascular endothelial functions of patients. Both authors have read and approved the final manuscript.

\section{Ethics approval and consent to participate}

The study was approved by the Ethics Committee of the 89th Hospital of the People's Liberation Army (Weifang, China). Patients who participated in this study or their guardians, signed informed consent and had complete clinical data.

\section{Patient consent for publication}

Not applicable.

\section{Competing interests}

The authors declare that they have no competing interests. 


\section{References}

1. Mogensen CE and Schmitz O: The diabetic kidney: From hyperfiltration and microalbuminuria to end-stage renal failure. Med Clin North Am 72: 1465-1492, 1988.

2. Büyükkoçak S, Oztürk HS, Tamer MN, Kaçmaz M, Çimen MYB and Durak I: Erythrocyte oxidant/antioxidant status of diabetic patients. J Endocrinol Invest 23: 228-230, 2000.

3. Bonnet $F$ and Cooper ME: Potential influence of lipids in diabetic nephropathy: Insights from experimental data and clinical studies. Diabetes Metab 26: 254-264, 2000

4. Ahn JH, Yu JH, Ko SH, Kwon HS, Kim DJ, Kim JH, Kim CS, Song KH, Won JC, Lim S, et al; Taskforce Team of Diabetes Fact Sheet of the Korean Diabetes Association: Prevalence and determinants of diabetic nephropathy in Korea: Korea national health and nutrition examination survey. Diabetes Metab J 38: 109-119, 2014.

5. Mima A: Inflammation and oxidative stress in diabetic nephropathy: New insights on its inhibition as new therapeutic targets. J Diabetes Res 2013: 248563, 2013.

6. Wada J and Makino H: Inflammation and the pathogenesis of diabetic nephropathy. Clin Sci (Lond) 124: 139-152, 2013.

7. Duran-Salgado MB and Rubio-Guerra AF: Diabetic nephropathy and inflammation. World J Diabetes 5: 393-398, 2014.

8. Jian W, Peng W, Xiao S, Li H, Jin J, Qin L, Dong Y and Su Q: Role of serum vaspin in progression of type 2 diabetes: A 2-year cohort study. PLoS One 9: e94763, 2014.

9. Šenolt L, Polanská M, Filková M, Cerezo LA, Pavelka K, Gay S, Haluzík M and Vencovský J: Vaspin and omentin: New adipokines differentially regulated at the site of inflammation in rheumatoid arthritis. Ann Rheum Dis 69: 1410-1411, 2010.

10. Phalitakul S, Okada M, Hara Y and Yamawaki H: Vaspin prevents TNF- $\alpha$-induced intracellular adhesion molecule-1 via inhibiting reactive oxygen species-dependent $\mathrm{NF}-\kappa \mathrm{B}$ and $\mathrm{PKC} \theta$ activation in cultured rat vascular smooth muscle cells. Pharmacol Res 64: 493-500, 2011.

11. Karbek B, Bozkurt NC, Topaloglu O, Aslan MS, Gungunes A, Cakal E and Delibasi T: Relationship of vaspin and apelin levels with insulin resistance and atherosclerosis in metabolic syndrome. Minerva Endocrinol 39: 99-105, 2014.
12. Molitch ME, DeFronzo RA, Franz MJ, Keane WF, Mogensen CE and Parving HH; American Diabetes Association: Diabetic nephropathy. Diabetes Care 26 (Suppl 1): S94-S98, 2003.

13. Giannakopoulos B, Gao L, Qi M, Wong JW, Yu DM, Vlachoyiannopoulos PG, Moutsopoulos HM, Atsumi T, Koike T, Hogg P, et al: Factor XI is a substrate for oxidoreductases: Enhanced activation of reduced FXI and its role in antiphospholipid syndrome thrombosis. J Autoimmun 39: 121-129, 2012.

14. Alzahrani SH and Ajjan RA: Coagulation and fibrinolysis in diabetes. Diab Vasc Dis Res 7: 260-273, 2010.

15. Henry ML, Davidson LB, Wilson JE, McKenna BK, Scott SA, McDonagh PF and Ritter LS: Whole blood aggregation and coagulation in $\mathrm{db} / \mathrm{db}$ and ob/ob mouse models of type 2 diabetes. Blood Coagul Fibrinolysis 19: 124-134, 2008.

16. Sun $X$, Zhou $X$ and Yan H: Hypercoagulation aggravates renal dysfunction in patient with diabetic nephropathy. Zhonghua Xue Ye Xue Za Zhi 22: 476-477, 2001 (In Chinese).

17. Patrassi GM, Martinelli S, Picchinenna A and Girolami A: Contact phase of coagulation in diabetes mellitus after aspirin administration. Folia Haematol Int Mag Klin Morphol Blutforsch 112: 333-338, 1985.

18. Patrassi GM, Vettor R, Padovan D and Girolami A: Contact phase of blood coagulation in diabetes mellitus. Eur J Clin Invest 12: 307-311, 1982.

19. Chen VM and Hogg PJ: Allosteric disulfide bonds in thrombosis and thrombolysis. J Thromb Haemost 4: 2533-2541, 2006.

20. Emsley J, McEwan PA and Gailani D: Structure and function of factor XI. Blood 115: 2569-2577, 2010.

This work is licensed under a Creative Commons

Attribution-NonCommercial-NoDerivatives 4.0 International (CC BY-NC-ND 4.0) License. 